\title{
An Empirical Study on the Impact of Organizational Justice on the Organizational Citizenship Behavior of the New Generation of Employees
}

\author{
Peng-Cheng GAO a and Zuo-Wei ZHOU b, \\ Harbin University of Technology, Harbin, Heilongjiang, China \\ apengchenggao1026@sina.com, bzhouzuowei@126.com \\ ${ }^{*}$ Corresponding author
}

\begin{abstract}
Keywords: The new generation of employees, Organizational justice, Organizational citizenship behavior.
\end{abstract}

\begin{abstract}
As the main support of the new century, the attitudes and behaviors of the new generation of employees have attracted much attention. Through the methods of literature research, questionnaire survey, correlation analysis and regression analysis, this paper finally discovered: distributive justice, procedural justice and interactional justice have significant positive effects on organizational responsibility and interpersonal facilitation in organizational citizenship behavior; and by establishing a regression equation, it is found that distributive justice and interactional justice have a more significant effect on organizational citizenship behavior. In the end, some suggestions on how to manage the new generation of employees are proposed: managers need to improve the organizational rules and regulations, establish a fair and equitable work environment; and managers should improve their leadership style and adhere to the "people-oriented" approach.
\end{abstract}

\section{Introduction}

The 21th century is a new century in which the economy is highly developed and talents and technology are equally important. With the accelerating pace of economic globalization, talent has become the key for enterprises to obtain a huge competitive advantage.

With the development of society, the new generation of employees has risen. Currently in China, the new generation refers to people born in the 1980s and beyond, mainly referring to $80 \mathrm{~s}$ and $90 \mathrm{~s}$ (Wang Lixia, 2013). Compared with previous generations, the value orientation of the new generation of employees is more diversified, more respectful for freedom and justice, but whoes sense of responsibility is weaker (Li Guangming, Zhou Guohua, 2013).

At present, scholars at home and abroad have studied organizational behavior in a variety of ways. Research on organizational citizenship behavior has proven that such behaviour can effectively improve organizational effectiveness and the relationship between the organizational environment (M. Brito Duarteh, 2015), so corporate managers are keen to stimulate employees to show more organizational citizenship behavior.

Scholars have verified a significant relationship between organizational justice and organizational citizenship behavior through a large number of empirical studies. However, in China, the impact of them for the new generation of employees is not deep. Consequently, this study empirically explores it, and provides inspiration for managers to improve the perception of fairness of the new generation of employees, to create a fair atmosphere, and to actively promote organizational citizenship behavior.

\section{Theoretical Basis and Research Hypothesis}

The "new generation" is a term used to describe the geological age, but with the progress of the society, it has been given more new concepts. By summarizing the literature, the new generation are defined as "post-80s" and "post-90s" who have received higher education, have more diversified values and advocate freedom and equality (Zhou Wenbin, Zhang Ping, 2013). 
Organizational justice refers to people's fair perception of organizational environment and their behavioral responses to these feelings. At present, researchers at home and abroad still have different views on the constituent elements of organizational justice. The organizational justice is divided into three dimensions[1]: distributive justice, procedural justice and interactive justice.

Organ defines organizational citizenship behavior as a voluntary individual behavior, which is not directly or explicitly rewarded by the formal reward system in the organization, but improves the effective operation of the organization in general[2]. Scholars have different opinions on the structure of organizational citizenship behavior. In 2005, referring to the model of Farth et al. (2004), Wu Xin divides 10 dimensions of organizational citizenship behavior into three levels: individual level, interpersonal level and organizational level, and defines them as "Organizational responsibility", "Interpersonal promotion" and "Work dedication".

Since the 1970s, scholars have explored the relationship between organizational justice and OCB, and found that organizational justice is the main influence factor (Colquitt, 2001). In 1988, Organ proposed the concept of organizational citizenship behavior, he pointed out the positive correlation between organizational justice and organizational citizenship behavior. The researcher Farth, Early $\&$ Lin (1997), taking the employees in Taiwan as an example, found that the procedure justice and distributive justice has positive correlation with organizational citizenship behavior. Domestic scholars have also made preliminary explorations of this issue. Among them, Fan Jingli et al. (1997), as the representative, studied it in the Chinese background, and found that the distributive justice and procedural justice are related to the organizational citizenship behavior of the organizational members who accept modern culture and have stronger values.

Based on these theories, the following assumptions are proposed.

H1: Organizational justice of the new generation employees have significant positive effects on each dimension of organizational citizenship behavior.

H1-1: Distribution justice have significant positive effects on OCB.

H1-2: Procedural justice have significant positive effects on OCB.

H1-3: Interaction justice have significant positive effects on OCB.

The overall theoretical framework of this study is shown in figure 1.

\begin{tabular}{|c|c|}
\hline $\begin{array}{l}\text { Organizational justice } \\
\text { Distributive justice } \\
\text { Procedural justice } \\
\text { Interactive justice }\end{array}$ & $\begin{array}{c}\text { Organizational citizenship behavior } \\
\text { Organizational responsibility } \\
\text { Interpersonal promotion } \\
\text { Work dedication }\end{array}$ \\
\hline
\end{tabular}

Fig. 1 The theoretical framework of this paper

\section{Data Collection and Variable Measurement}

The influence of organizational justice on organizational citizenship behavior of the new generation of employees is discussed, and the effective questionnaire survey is used to collect information. A total of 195 questionnaires and 154 valid questionnaires are collected, with an effective rate of $79 \%$. Considering that the new generation of employees grow up with the network, the distribution and collection of questionnaires are all network methods. The scope of which is mainly concentrated in several cities, such as Jining, Shandong Province and Wuhan, Hubei Province.

\section{Interpretation of Result}

\section{Analysis of Reliability and Validity}

In order to test whether the scale can accurately and reliably reflect the true feelings of the sample, researchers used to analyze the reliability and validity of the scale.

The Cronbach's $\alpha$ coefficient is the most common reliability coefficient at present. When the mean of correlation coefficient is higher, and the intrinsic reliability of the item is higher. Through 
analysis, the overall Cronbach's $\alpha$ value of the organizational justice scale is far greater than 0.7. Therefore, the internal reliability of the evaluation system is ideal in general.

Then the validity of the scale is tested. In order to analyze the structural validity, researchers usually use factor analysis. The KMO value and Bartlett test of sphericity test are calculated. According to the results, the probability value of Bartlett sphericity test statistic is 0.000 . It can be concluded that there are significant differences between the correlation coefficient matrix and the unit matrix. The KMO value is greater than 0.7 , so the original variable is suitable for factor analysis.

\section{Descriptive Statistical Analysis}

The analysis of the data usually begins with the basic statistical analysis. Through the basic statistical analysis, we can grasp the general distribution state of the data and the basic statistical characteristics. The results are shown in Table 1.

Table 1 Effective demographic and histological characteristics of subjects

\begin{tabular}{|c|c|c|c|}
\hline Attribute & Classification & Frequency & Percentage \\
\hline \multirow{2}{*}{$\begin{array}{l}\text { Number of years } \\
\text { of birth }\end{array}$} & 1980-1989 & 80 & 51.9 \\
\hline & 1990-1999 & 74 & 48.1 \\
\hline \multirow{4}{*}{$\begin{array}{l}\text { Degree of } \\
\text { education }\end{array}$} & Below junior college & 53 & 34.4 \\
\hline & Junior college & 36 & 23.4 \\
\hline & Undergraduate & 63 & 40.9 \\
\hline & Above Master & 2 & 1.3 \\
\hline \multirow{4}{*}{ Working years } & Less than one year & 54 & 35.1 \\
\hline & 1 year-less than 5 years & 32 & 20.8 \\
\hline & 5 years-less than 10 years & 29 & 18.8 \\
\hline & More than 10 years & 39 & 25.3 \\
\hline
\end{tabular}

It can be seen from Table 1 that the survey subjects are mainly post-80s and post-90s workers, their educational level is not uniform, and the majority (about 65.6) of the respondents have received college education or above; The distribution of their working years is also uneven. Most of them (about 35.1) work less than one year, belonging to the stage of society, and some of subjects have been working for 5 years, and most of them are those who have received college education or less.

\section{Correlation Analysis}

The correlation analysis of variables can make clear the degree of statistical relationship between factors. The most common one is Pearson correlation coefficient. The results are shown in Table 2.

Table 2 Correlation between organizational justice Dimension and organizational Citizenship behavior

\begin{tabular}{cccccccc}
\hline & & $\begin{array}{c}\text { Distribution } \\
\text { Justice }\end{array}$ & $\begin{array}{c}\text { Procedural } \\
\text { Justice }\end{array}$ & $\begin{array}{c}\text { Interactive } \\
\text { Justice }\end{array}$ & $\begin{array}{c}\text { Organizational } \\
\text { responsibility }\end{array}$ & $\begin{array}{c}\text { Interpersonal } \\
\text { promotion }\end{array}$ & $\begin{array}{c}\text { Work } \\
\text { dedication }\end{array}$ \\
\hline Distribution & Pearson & 1 & $.812^{* *}$ & $.752^{* *}$ & $.467^{* *}$ & $.526^{* * *}$ & -.009 \\
Justice & Significant & & .000 & .000 & .000 & .000 & .916 \\
Procedural & Pearson & & 1 & $.881^{* *}$ & $.457^{* *}$ & $.557^{* *}$ & -.022 \\
Justice & Significant & & & .000 & .000 & .000 & .791 \\
Interactive & Pearson & & & 1 & $.511^{* *}$ & $.596^{* *}$ & .012 \\
Justice & Significant & & & & .000 & .000 & .882 \\
Organizational & Pearson & & & & 1 & $.815^{* *}$ & $.239^{* *}$ \\
responsibility & Significant & & & & & .000 & .003 \\
Interpersonal & Pearson & &. & & & 1 & $.179^{*}$ \\
promotion & Significant & & & & & & .026 \\
Work & Pearson & & & & & & 1 \\
dedication & Significant & & & & & & \\
\hline
\end{tabular}

Note: $* * p<.01 . * \mathrm{p}<.05$ (two-tailed tests) 
As can be seen from the table 2, there is a significant positive correlation between organizational justice and organizational responsibility, interpersonal promotion. When the significant level is 0.05 , the linear correlation among the factors can be considered. Although there is a certain correlation between the dimensions of organizational justice and work dedication, the correlation coefficient is low, which may have a certain relationship with the characteristics of the new generation of employees. The new generation of employees advocate more freedom, so their feelings for the organization are not deep, and work dedication behaviors are weak.

\section{Regression Analysis and Hypothesis Testing}

Regression analysis is also an important method to analyze the relationship between variables. In order to further analyze the causality between variables, regression analysis is needed[6].

Table 3 Regression analysis of organizational justice on organizational responsibility

\begin{tabular}{|c|c|c|c|c|c|c|c|c|c|c|}
\hline & \multirow{2}{*}{ model } & \multicolumn{2}{|c|}{$\begin{array}{l}\text { Non-standardized } \\
\text { coefficient }\end{array}$} & \multirow{2}{*}{$\begin{array}{c}\text { Standard } \\
\text { coefficient } \\
\text { trial version }\end{array}$} & \multirow{2}{*}{$\mathrm{t}$} & \multirow{2}{*}{ Sig. } & \multirow{2}{*}{$\mathrm{F}$} & \multirow{2}{*}{ Sig. } & \multirow{2}{*}{$\begin{array}{c}\mathrm{R} \\
\text { square }\end{array}$} & \multirow{2}{*}{$\begin{array}{l}\text { adjust } \\
\text { R square }\end{array}$} \\
\hline & & $\mathrm{B}$ & Standard error & & & & & & & \\
\hline \multirow{4}{*}{1} & (constant) & 2.611 & .231 & & 11.287 & .000 & \multirow{4}{*}{19.395} & \multirow{4}{*}{.000} & \multirow{4}{*}{.279} & \multirow{4}{*}{.265} \\
\hline & $\begin{array}{l}\text { Distribution } \\
\text { Justice }\end{array}$ & .194 & .100 & .233 & 1.942 & .054 & & & & \\
\hline & $\begin{array}{l}\text { Procedural } \\
\text { Justice }\end{array}$ & -.097 & .131 & -.124 & -.741 & .460 & & & & \\
\hline & $\begin{array}{l}\text { Interactive } \\
\text { Justice }\end{array}$ & .344 & .114 & .445 & 3.012 & .003 & & & & \\
\hline
\end{tabular}

Note: a. dependent variables: organizational responsibility

As can be seen from Table 3, organizational responsibility is primarily related to distributive justice. In the significance test of regression equation, the probability value of $F$ statistic is close to 0 , and the linear relationship between the explained variable and the explanatory variable is considered to be significant. Thus, it is assumed that H1-1 can be verified.

Table 4 Regression analysis of organizational justice on interpersonal promotion

\begin{tabular}{|c|c|c|c|c|c|c|c|c|c|c|}
\hline & \multirow[t]{2}{*}{ model } & \multicolumn{2}{|c|}{$\begin{array}{l}\text { Non-standardized } \\
\text { coefficient }\end{array}$} & \multirow{2}{*}{$\begin{array}{c}\text { Standard } \\
\text { coefficient } \\
\text { trial version }\end{array}$} & \multirow[t]{2}{*}{$\mathrm{t}$} & \multirow[t]{2}{*}{ Sig. } & \multirow[t]{2}{*}{$\mathrm{F}$} & \multirow[t]{2}{*}{ Sig. } & \multirow{2}{*}{$\begin{array}{c}\mathrm{R} \\
\text { square }\end{array}$} & \multirow{2}{*}{$\begin{array}{c}\text { adjust } \\
\text { R square }\end{array}$} \\
\hline & & B & Standard error & & & & & & & \\
\hline \multirow{4}{*}{1} & (constant) & 2.515 & .207 & & 12.144 & .000 & \multirow{4}{*}{29.311} & \multirow{4}{*}{.000} & \multirow{4}{*}{.370} & \multirow{4}{*}{.357} \\
\hline & $\begin{array}{l}\text { Distribution } \\
\text { Justice }\end{array}$ & .134 & .089 & .168 & 1.502 & .135 & & & & \\
\hline & $\begin{array}{l}\text { Procedural } \\
\text { Justice }\end{array}$ & .021 & .117 & .029 & .184 & .855 & & & & \\
\hline & $\begin{array}{l}\text { Interactive } \\
\text { Justice }\end{array}$ & .329 & .102 & .445 & 3.215 & .002 & & & & \\
\hline
\end{tabular}

Note: b. dependent variables: interpersonal promotion

From the significant test of regression coefficient $F$ statistics and $t$ statistics, we can see that there is a significant linear relationship between interpersonal promotion and interactive justice. Thus, it is assumed that $\mathrm{H} 2-2$ can be verified.

Through comparative analysis, we can find that interactive justice has stronger explanation for OCB. This may have something to do with the new generation of employees, who advocate more freedom and equality. Based on the above analysis, the organizational citizenship behavior will be more abundant when the organization managers make greater efforts to create the interaction justice. 
Table 5 Regression analysis of organizational equity on work dedication

\begin{tabular}{|c|c|c|c|c|c|c|c|c|c|c|}
\hline \multirow{2}{*}{\multicolumn{2}{|c|}{ model }} & \multicolumn{2}{|c|}{$\begin{array}{l}\text { Non-standardized } \\
\text { coefficient }\end{array}$} & \multirow{2}{*}{$\begin{array}{c}\text { Standard } \\
\text { coefficient } \\
\text { trial version }\end{array}$} & \multirow[t]{2}{*}{$\mathrm{t}$} & \multirow[t]{2}{*}{ Sig. } & \multirow[t]{2}{*}{$\mathrm{F}$} & \multirow[t]{2}{*}{ Sig. } & \multirow{2}{*}{$\begin{array}{c}\mathrm{R} \\
\text { square }\end{array}$} & \multirow{2}{*}{$\begin{array}{c}\text { adjust } \\
\text { R square }\end{array}$} \\
\hline & & $\mathrm{B}$ & Standard error & & & & & & & \\
\hline \multirow{4}{*}{1} & (constant) & 3.882 & .333 & & 11.652 & .000 & \multirow{4}{*}{.243} & \multirow{4}{*}{.867} & \multirow{4}{*}{.005} & \multirow{4}{*}{-.015} \\
\hline & $\begin{array}{l}\text { Distribution } \\
\text { Justice }\end{array}$ & .012 & .144 & .012 & .082 & .934 & & & & \\
\hline & $\begin{array}{l}\text { Procedural } \\
\text { Justice }\end{array}$ & -.146 & .188 & -.152 & -.773 & .441 & & & & \\
\hline & $\begin{array}{l}\text { Interactive } \\
\text { Justice }\end{array}$ & .130 & .165 & .137 & .789 & .431 & & & & \\
\hline
\end{tabular}

Note: c. dependent variables: work dedication

From the significant test of regression coefficient $F$ statistics, The linear relationship between organizational justice and work dedication is not significant, so the linear model can not be established. Thus, it is assumed that H1-3 cannot be verified.

\section{Discussions and Recommendations}

With the development of society, people pay more and more attention on organizational justice, at the same time, the enterprise's expectations for its employees are rising. In this context, to achieve mutual benefit and win each other, the organization must take effective measures[5].

\section{Improve the Rules and Regulations and Establish a Fair Environment}

The employee's position on the job and his behavior at work will be affected by organizational justice, which will further affect the performance. Therefore, it is urgent to solve the problem of organizational justice.

The establishment of a good atmosphere of organizational justice needs to take into account the influence of various factors. For distributive justice, the organization needs to establish a transparent, fair and open compensation system, so that employees can feel that a high level of work commitment can be rewarded with reasonable and satisfactory compensation. For procedure justice, organization managers should encourage the new generation of employees to participate in decision-making and discussion, and enhance their sense of ownership. For the interaction justice, organization manager can construct an effective complaint system and provide a feedback platform for the new generation of employees.

\section{Improve Leadership Style and Create a "People-Oriented" Corporate Culture}

In 1993, Greenberg pointed out that employee's sense of interactive justice stems from the process of interacting with the organization's managers. The maintenance of good relationship will contribute to the formation of psychological contract of employees[1]. Therefore, managers need to show respect and trust for employees when they interact with employees, so in return, employees will show their organizational citizenship behavior independently. At the same time, improving the leadership style is a compulsory course for manager. Nowadays, the society emphasizes "people", so it is inevitable for the development of times to create the "people-oriented" culture in enterprises.

\section{Acknowledgement}

This research was financially supported by Harbin Institute of Technology (Weihai) Social Science Fund imjq10100068.

\section{References}

[1] Ming-xing Jin. An Empirical Study on the Impact of Organizational justice on Organizational Citizenship Behavior and Job Performance: A Questionnaire Based on Financial Firms[D]. Fudan University, 2011. 
[2] Organ,D.W. Organizational Citizenship Behavior: The Good Soldier Syndrome[M]. Lexington.MA: Lexing-ton Books. 1988.

[3] Hui Cao, Hui-ping Liang. The Impact of Employee Justice on Organizational Citizenship Behavior: The Intermediary Role of Organizational Support[J]. Science and Technology Management Research, 2010 (14):186-190.

[4] Guang-ming Li, Guo-hua Zhou. A Structural Equation Model Analysis for University Teachers' Organizational identity[J]. Educational Administration of Colleges and Universities. 2013 (01): 67-71.

[5] Zhen-xi Niu, Shu-yan Gong. Prospect of New Generation of Employee Management Based on Self-identity Theory[J] .Qinghai Social Sciences. 2013 (02):118-120.

[6] Lai-bin Qi, Yi-hui Zhang, You-zeng Zheng. Reliability and Validity of the Questionnaire[J] .Contemporary Educational Science. 2003, 22.

[7] Wen-bin Zhou, Ping Zhang, Ming-ya Jiang. A Study on the Engagement of the New Generation of Employees in Chinese Enterprises: from the Perspective of Salary Satisfaction[J]. Economic Management, 2013 (10):77-90. 